\title{
Response to letter regarding "Evidence of natural occurence of the banned antibiotic chloramphenicol in herbs and grass"
}

\author{
Alida A. M. Stolker • Bjorn Berendsen • \\ Michel W. F. Nielen
}

Published online: 12 January 2011

(C) The Author(s) 2011. This article is published with open access at Springerlink.com

We were surprised to read that the natural occurrence of chloramphenicol (CAP) was reported as long ago as 2003 by Hanekamp et al. [1]. We missed that information, probably because their findings were not published in a peer-reviewed journal. In our paper [2], we did not claim to be the first to suggest the natural occurrence of CAP; on the contrary, we included several references from earlier studies. We stated that our paper was the first to describe the detection of CAP in plant materials, sample material which had not been addressed before. Furthermore, there is an important issue which is not raised by Hanekamp et al. and that is the issue of "criteria for confirmation of the identity of a compound'. In EU legislation, viz. Commission Decision 2002/657/EC, it is described how to confirm the identity of a banned compound, such as CAP. The confirmation of the identity of a compound should comply with the identification points approach. A suitable way is the use of tandem mass-spectrometric detection in which two (specific) product ions are monitored and the ion ratios have to be within a predefined tolerance interval. Although Hanekamp et al. suggested the natural occurrence of CAP in 2003, it is also important to mention that their findings were not supported by confirmatory analysis and validation data.
Theoretically, it cannot be excluded that the results published at that time should be regarded as false positives.

In summary, in our opinion we were the first to publish fully confirmed non-compliant findings (according to 2002/ $657 / \mathrm{EC}$ ) of the natural occurrence of CAP in plant materials. Nevertheless, we do think Hanekamp et al. have an interesting opinion about the established 'tolerance levels' of banned antibiotics and we appreciate their contribution.

Open Access This article is distributed under the terms of the Creative Commons Attribution Noncommercial License which permits any noncommercial use, distribution, and reproduction in any medium, provided the original author(s) and source are credited.

\section{References}

1. Hanekamp JC, Kwakman JHJM, Olieman K (2011) Anal Bioanal Chem 399. doi: 10.1007/s00216-010-4593-8

2. Berendsen B, Stolker L, de Jong J, Nielen M, Tserendorj E, Sodnomdarjaa R, Cannavan A, Elliott C (2010) Anal Bioanal Chem 397:1955-1963
This article is the response to the 'Letter to the Editor' to be found at http://dx.doi.org/10.1007/s00216-010-4593-8

A. A. M. Stolker $(\triangle) \cdot$ B. Berendsen $\cdot$ M. W. F. Nielen RIKILT, Wageningen UR,

Akkermaalsbos 2, P.O. Box 230, 6700 AE Wageningen,

The Netherlands

e-mail: linda.stolker@wur.nl 